муниципального района, главы муниципального образования, главы местной администрации.

Таким образом, на примере муниципальных правовых систем можно применять методологические основы системно-структурного подхода.

1. Словарь иностранных слов. М., 1986. С.459.

2. Афанасьев В.Г. Системность и общество. М., 1980. С.21,23

3. Игнатюк Н.А., Замотаев А.А., Павлушкин А.В. Муниципальное право. М., 2005 // СПС «Консультант Плюс».

4. Пешин Н.Л. Государственная власть и местное самоуправление в России: проблемы развития конституционно-правовой модели. М., 2007 // СПС «Консультант Плюс».

5. Муниципальное право. М., 2005. С.46.

\title{
Деманова С.B. \\ Образование в Республике Ирак: правовые и социальные аспекты
}

Саратовский национальный исследовательский государственный университет имени Н.Г. Чернышевского (Россия, Саратов)

doi: $10.18411 / \mathrm{lj}-31-08-2017-02$

idsp: 000001:lj-31-08-2017-02

\section{Аннотация}

В представленной статье обозначены некоторые правовые и социальные аспекты, связанные с получением образования в Республике Ирак. На основе анализа норм Конституции Ирака 2005 года и законодательства об образовании сделан вывод, что на конституционном уровне в Иракской Республике закреплено право на получение бесплатного образования всех уровней (начальное общее, основное общее, среднее общее, среднее профессиональное, высшее образование). Однако, реализация права на образование в Ираке спряжена с рядом трудностей, а именно: нестабильная политическая обстановка, продолжающиеся военные действия, террористические акты, недостаточное бюджетное финансирование, обычаи и традиции, отсутствие заинтересованности, бедность населения и др.

Ключевые слова: Конституция Республики Ирак, право на образование, образование девочек (девушек, женщин), субъекты образовательного процесса, уровни образования.

\section{Abstract}

The article highlights some legal and social aspects related to education in the Republic of Iraq. On the basis of analysis of provisions of the Iraqi Constitution of 2005 and law on education, it is concluded that the right to free education at all levels (primary general education, basic general education, secondary general education, vocational secondary education, higher education) is enshrined at the constitutional level in the Republic of Iraq. However, the implementation of the right to education in Iraq is connected with a number of difficulties, i.e. the unstable political situation, ongoing military actions, terrorist acts, the lack of budgetary funds, customs and traditions, the lack of interest, poverty, etc.

Key words: the Constitution of the Republic of Iraq, the right to education, the education of girls (women), subjects of the educational process, levels of education.

Образование, вне всякого сомнения, играет огромную роль в жизни каждого человека и общества в целом. Его основной задачей является формирование внутреннего мира и самосознания человека, раскрытие личностных качеств. Благодаря образованию происходит социализация и инкультурация индивида. 
От уровня образования населения зависит конкурентоспособность государства в политической, экономической, социальной и культурной сферах.

К сожалению, по оценкам ЮНЕСКО такие страны как Ирак, Египет, Марокко, Мавритания, Судан, Йемен входят в список 34 стран, где уровень неграмотности населения более 10 млн человек [1, с.48]. И, хотя в докладе ООН сообщается, что за последнее десятилетие Ирак добился снижения доли неграмотных на 41\%, по-прежнему сохраняется достаточно большой разрыв в уровне грамотности между мужчинами и женщинами. Кроме того, доля неграмотных в сельской местности составляет $21 \%$, что в семь раз больше доли неграмотных обоего пола в городах [2].

В настоящее время образование занимает одну из ключевых позиций в развитии общества в Ираке и призвано подготовке будущего поколения к решению государственных задач.

Как отмечают некоторые исследователи в арабских странах, до сих пор, несмотря на распад Советского Союза, ценятся дипломы, полученные в России [3, с.309].

Необходимо отметить, что Россию и Республику Ирак связывают давние партнерские отношения в гуманитарной сфере. Так, например, 22 июня 1973 года был подписан Договор о взаимном оказании правовой помощи между Союзом Советских Социалистических Республик и Иракской Республикой [4]. Таким образом, документы об образовании, выданные образовательными организациями Ирака, имеют законную силу на территории Российской Федерации без какого-либо дополнительного удостоверения. Другими словами, не требуют ни консульской легализации, ни апостилирования. Это означает, что переводы и копии документов могут быть заверены нотариусом в стране выдачи документов. Также с 12 февраля 1972 года действует Протокол об эквивалентности ученой степени кандидата наук, присваиваемой в Союзе и Советских Социалистических Республик, и ученой степени доктора философии (Ph.D), признанной в Иракской Республике [4].

В настоящее время в России обучаются примерно 1,4 тыс. иракских граждан. Граждане из Республики Ирак получают высшее образование по программам бакалавриата, специалитета, магистратуры и подготовки кадров высшей квалификации как за счет бюджетных ассигнований федерального бюджета в пределах установленной квоты, так и за счет средств физических и юридических лиц в соответствии с договорами об оказании платных образовательных услуг. Следует отметить тот факт, что ежегодно размер квоты на образование в Российской Федерации иностранных граждан, получаемый в образовательных организациях по образовательным программам среднего профессионального образования, высшего образования и дополнительного профессионального образования за счет бюджетных ассигнований федерального бюджета составляет 15 тыс. человек [5]. Таким образом, данная мера способствует популяризации высшего образования в мировом образовательном пространстве, в т.ч. и в Ираке.

Так, например, в 2013-2014 учебном году Минобрнауки России предоставило Республике Ирак 150 квот на образование[6].

Ирак - одно из самых молодых федеративных государств в мире. Государственнотерриториальное устройство в этой стране существенно изменилось в результате международного вмешательства, сопровождавшегося военной интервенцией со стороны государств-участников блока НАТО в 2003 году. В настоящее время территория Ирака разделена на 18 мухафаз, три из которых находятся в составе Курдистанского Региона). Статус Курдистанского Региона в составе федеративного Ирака окончательно не определен. Фактически на территории, контролируемой Курдистанским региональным правительством (Kurdistan Regional Government), федеральные органы не имеют реальной власти [7, с.15]. Данное обстоятельство играет важную роль и в процессе формирования органов управления системой образования Республики Ирак. 
В сфере образования Иракской Республики действуют два министерства: Министерство образования и Министерство высшего образования и научных исследований. Министерство образования осуществляет контроль за дошкольным и общим образованием (начальным, основным, средним общим). На региональном уровне созданы Генеральные департаменты по образованию, которые обеспечивают функционирование системы дошкольного и общего образования. Министерство образования проводит аккредитацию образовательных организаций общего образования. Оценка качества в системе высшего образования входит в компетенцию Министерства высшего образования и научных исследований. В Курдистане действует Министерство образования Курдистана.

Принятая в 2005 году Конституция Иракской Республики, по мнению Г.З. А. Аль Мухамеда, положила начало новому этапу политико-правового развития страны [9]. В соответствии с ч.2 статьи 29 «дети имеют право на воспитание, заботу и получение образования». Статья 34 устанавливает, что «образование является основополагающим фактором в развитии общества и правом, гарантированным государством. Начальное образование является общеобязательным.... Получение бесплатного образования на всех уровнях - право каждого гражданина Ирака» [10].

Таким образом, на конституционном уровне в Иракской республике закреплено право на получение бесплатного образования всех уровней (начальное общее, основное общее, среднее общее, среднее профессиональное, высшее образование). Для обеспечения данного права необходимы значительные материально-финансовые затраты и административно-организационные ресурсы государства.

Закон об обязательном начальном образовании № 118 от 1976 года (далее Закон №118) определяет, что обучение является основным правом человека, обязательным и всеобъемлющим..... Образование - основная необходимость для закладки цивилизации и ее прогресса Арабское общество особенно сильно нуждается в образовании для формирования общественного сознания и для поднятия культуры и социального развития [11]. Несмотря на то, что Закон №118 был принят в 1976 году, его нормы коррелируются с нормами действующей Конституции Ирака 2005 года.

Необходимо отметить, что в Закон №118 были внесены изменения Законом №116 от 1987 года. Изменения были связаны с внедрением в образовательный процесс специального обучения для детей с ограниченными возможностями здоровья (нарушениями зрения, слуха и др.). Однако, несмотря на изменения в законодательстве об образовании, наблюдается более низкая посещаемость среди девочек специализированных образовательных организаций для детей с особенностями психофизического развития. Данное обстоятельство обусловлено тем, что многие семьи опасаются за здоровье и жизнь девочек-инвалидов, которых могут обидеть или похитить.

Следует отметить, что образование девочек (девушек, женщин) является одним из ключевых направлений образовательной политики Ирака. Большинство девочек (девушек) посещают однополые школы, однако некоторые посещают школы и классы, где ведется совместное обучение мальчиков и девочек, например в Курдистане.

Начальное образование является в Ираке бесплатным и обязательным для всех детей, которые достигли возраста 6 лет. Законом об обязательном начальном образовании закреплена обязанность родителей по определению ребенка в школу и обеспечению его начальным образованием. Ежегодно в школах составляются списки детей по месту жительства. Законодательство обязывает школы предоставить все необходимые условия для записи дошкольников в школу на бесплатной основе. Запись ребенка в школу осуществляется на бесплатной основе. К сожалению, некоторые дети в возрастной группе от 6 до 12 лет не поступают в школу или не завершают начальное общее образование. В городах этот показатель оставляет $16 \%$, в сельских районах - 41\%. Данное обстоятельство обусловлено рядом причин: обычаи и традиции, отсутствие заинтересованности и бедность населения. Так, например, 24\% девочек не учатся в школе из-за отсутствия 
заинтересованности у семьи, $13 \%$ не посещают школу из-за бедности. Более $60 \%$ матерей в сельских районах (в городах более 40\%) имеют твердое убеждение, что образование сыновей имеет приоритет по сравнению с образованием дочерей. Еще одной проблемой является рост насилия в отношении девочек. В некоторых районах добираться до школы небезопасно, поэтому необходимо сопровождать девочек в школу кому-то из членов семьи либо использовать личный транспорт, который зачастую отсутствует [2].

Кроме того, многие школьные здания требуют капитального ремонта, например $70 \%$ школ испытывают недостаток в чистой воде и туалетах. В школах не хватает специализированных лабораторий, библиотек и иного оборудования. Остро ощущается нехватка педагогических кадров.

Что касается высшего образования, то, как отмечают некоторые исследователи, обучение в большинстве университетов организовано по двухуровневой системе (бакалавриат и магистратура). Одной из главных проблем арабского высшего образования является спад его качества, сильное отставание от европейского образования, особенно в технических областях [1].

Так, например, в Ираке ведут свою образовательную деятельность порядка 30 государственных университетов, в т.ч. 10 университетов Курдистана. Наряду с государственными университетами высшее образование можно получить в частных образовательных организациях, которых в Ираке более 20. Необходимо отметить, что Багдадский университет является ведущим университетом, а также занимает первое место в Ираке и 501 место в мировом рейтинге QS[8].

Закон Министерства высшего образования и научных исследований № 40 от 04.04.1988 года регулирует непосредственно деятельность министерства, определяет общие правила функционирования системы высшего образования и осуществления образовательной и научной деятельности, а также определяет правовое положение участников отношений в сфере высшего образования[12].

В 2016 году был принят Закон о высшем образовании № 25, который определяет основные направления образовательной политики Ирака (распространение знаний в Ираке, проведение научный исследовании и др.) [13].

К освоению программ высшего образования допускаются лица, имеющие сертификат о среднем общем образовании или диплом об окончании средней профессиональной (технической) образовательной организации. Зачисление в вузы происходит без сдачи вступительных испытаний. Прием на программы по направлениям медицина, архитектура, инженерное образование - на основании конкурса документов о среднем общем образовании.

Важно отметить тот факт, что в Ираке действуют два типа образовательных организаций высшего образования, а именно технические институты и университеты. Технические институты предлагают два типа образовательных программ: двухгодичные программы на получение диплома техника и четырехлетние программы на получение степени бакалавра. Университеты осуществляют обучение по образовательным программам, ведущим к получению степени бакалавра, степени магистра и степени Ph.D.

Успешное окончание бакалаврских программ по направлениям филологии, лингвистики и литературы ведет к получению степени бакалавра в области искусства (Bachelor of Arts). Выпускникам бакалаврских программ по направлениям естественных наук, сельскому хозяйству, инженерным наукам присуждается степень бакалавра в области естественных наук (Bachelor of Science). Сроки освоения образовательных программ бакалавриата составляют 4 года. По таким программам как стоматология, фармакология и ветеринарии - 5 лет. Обучение по программам в области медицины - 6 лет. После окончания бакалаврских программ студенты с наиболее высокими результатами могут продолжить обучение по программам магистратуры. Срок обучения в магистратуре составляет 2 года. После успешного окончания магистратуры студенты 
могут продолжить обучение в течении трех лет по программам на получение степени Ph.D.

Технические институты предлагают двухлетние программы, по окончании которых выпускники получают дипломы техников. Около 10\% выпускников данных образовательных организаций получают право продолжить обучение по программам бакалавриата в университетах по сокращенной программе. Необходимо отметить, что технические институты также предлагают четырехлетние программы на получение степени бакалавра. Условиями доступа на данный вид образовательных программ является наличие или сертификата о среднем общем образовании, или наличие диплома профессионального бакалавра [4].

Несмотря на сложную и нестабильную политическую обстановку, Республика Ирак осуществляет сотрудничество в сфере высшего образования со многими странами мира, в том числе и с Россией. В 2011-2012 годах был подписан ряд документов о сотрудничестве СГУ имени

Н.Г. Чернышевского с университетами Ирака в сфере разработки и реализации совместных проектов в научной, учебной, педагогической, управленческой деятельности; обмена студентами, аспирантами и преподавателями: договор о сотрудничестве с Университетом Вавилона, Меморандум о взаимопонимании между Университетом АльКадисия и СГУ, Соглашение об академическом и научном сотрудничестве между Университетом-Хавлер Салахаддина Эрбил (Курдистан, Ирак) и СГУ, договор о сотрудничестве между Тикритским университетом (Республика Ирак) и СГУ и др.

К сожалению, в Ираке продолжают гибнуть мирные жители, что приводит к вынужденной миграции как среди студентов, так и среди преподавателей. Некоторые студенты покидают Ирак для продолжения обучения в Иордании, Египте и других странах.

Таким образом, система образования Республики Ирак имеет свою уникальную структуру. Несмотря на значительные трудности правового и финансового характера система образования Ирака продолжает работать и развиваться. На конституционном уровне закреплена бесплатность всех уровней образования. Продолжающиеся военные действия, террористические акты, финансовые трудности по обеспечению образовательного процесса оказывают негативное влияние на реализацию конституционного права на получение образования. По-прежнему одной из острых проблем остается доступ к образованию девочек (девушек, женщин), особенно в сельской местности.

$$
* * *
$$

1. Лукичев Г.А. Развитие высшего образования в арабских странах (аналитический обзор) // Вестник высшей школы. 2008. №4. С.48-52.

2. ООН. Рассмотрение докладов, представленных государствами-участниками в соответствии со статьей 18 Конвенции о ликвидации всех форм дискриминации в отношении женщин. Объединенные четвертый, пятый и шестой периодические доклады государств-участников. Ирак. [электронный pecypc].

URL: http://docstore.ohchr.org/SelfServices/FilesHandler.ashx?enc=6QkG1d\%2FPPRiCAqhKb7yhsgA84bcFRy75 ulvS2cmS\%2F\%2Bjh8crC8ecZAYmHONLhdy\%2BrzfpRsiSEmRHg7ZbnOw4yEKmQv2IUXXCIN0Q37e MJstecxk0utijtFnGujzl8QMeV (дата обращения 26.07.2017).

3. Успенская Н.А. Высшее образование в арабских странах: прошлое настоящее [электронный ресурс]. URL: https://cyberleninka.ru/article/v/vysshee-obrazovanie-v-arabskih-stranah-proshloe-i-nastoyaschee (дата обращения 22.08.2017)

4. Договор о взаимном оказании правовой помощи между Союзом Советских Социалистических Республик и Иракской Республикой (подписан в г. Москве 22.06.1973); Протокол об эквивалентности ученой степени кандидата наук, присваиваемой в Союзе Советских Социалистических Республик, и ученой степени доктора философии (Ph.D), признанной в Иракской Республике от 12 февраля 1972 года. См.: Национальный информационный центр по вопросам признания образования и (или) квалификации, ученых степеней и званий, полученных в иностранном государстве. ФГБОУ 
«Главэкспертцентр» [Официальный сайт]. URL: http://nic.gov.ru/ru/inworld/countries/Iraq (дата обращения 22.08.2017).

5. Об установлении квоты на образование иностранных граждан и лиц без гражданства в Российской Федерации // СЗ РФ. 2013. №41. Ст. 5204.

6. Министерство иностранных дел Российской Федерации [официальный сайт]. URL: http://www.mid.ru/ru/maps/iq/?currentpage=main-country (дата обращения 22.08.2017).

7. Дубессан Рафед Х. Дубесан Реформа государственно-территориального устройства Республики Ирак в XXI веке: проблемы теории и практики (дис. ... канд. юрид. наук. Воронеж, 2014). 176 с.

8. Багдадский университет [официальный сайт]. URL: http://www.en.uobaghdad.edu.iq/ArticleShow.aspx?ID=1620 (дата обращения 22.08.2017). Прим. автора: составители рейтинга лучших вузов мира QS World University Rankings оценивают университеты по шести показателям: исследовательская деятельность, преподавание, мнение работодателей и карьерный потенциал, количество иностранных студентов и преподавателей.

9. Г.З. А. Аль - Мухамед Конституционная обязанность государства Ирак по защите прав и свобод граждан // Правовая наука и реформа юридического образования. 2011. №1 (24). С.58-61.

10. Конституция Ирака от 15 октября 2005 г. //Российский правовой портал: Библиотека Пашкова [Сайт]. URL: http://worldconstitutions.ru/?p=338 (дата обращения 10.11.2016)

11. Закон об обязательном начальном образовании № 118 от 1976 года // Министерство образования Республики Ирак [Официальный сайт]. URL: http://www.moedu.gov.iq/ (дата обращения: 20.08.2017).

12. Закон № 40 от 04.04.1988 года. Министерство высшего образования [Официальный сайт]. URL: http://mohesr.gov.iq/ (дата обращения 27.08.2017).

13. Закон № 252016 года О высшем образовании. Законы - Министерство высшего образования и

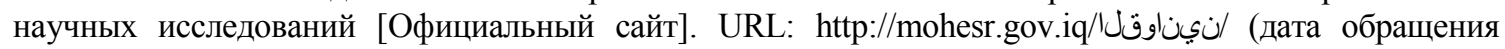
27.08.2017).

\section{Корсакова Т.И.}

\section{Специфика договора залога исключительных прав на объекты авторского права}

Ростовский государственный экономический университет (РИНХ) (Россия, Ростов-на-Дону)

doi: 10.18411/lj-31-08-2017-03

idsp: 000001:lj-31-08-2017-03

\section{Аннотация}

В статье анализируются основные проблемы, возникающие у сторон при заключении договора залога исключительных прав на объекты авторского права.

Автор дает практические рекомендации для обеспечения выполнения обязательств и снижению рисков участников данных правоотношений.

Ключевые слова: исключительные права, объекты авторского права, договор залога, интеллектуальная собственность, коммерциализация результатов интеллектуальной деятельности

В условиях формирования цифровой экономики наблюдается устойчивая тенденция роста сектора интеллектуальной собственности. Зачастую стоимость нематериальных активов компаний превосходит стоимость всех материальных активов и является основным ресурсом корпоративной маркетинговой стратегии. Коммерциализация интеллектуальной собственности актуализирует вопрос об обеспечении исполнения обязательств, в том числе, о залоге исключительных прав на объекты интеллектуальной собственности. Вопрос о залоге исключительных прав российской юридической наукой исследован недостаточно, особенно это касается категории объектов авторского права.

Исключительное право на объект авторского права появляется в момент создания произведения. Данный принцип соответствует международным требованиям и зарубежным договорам в области интеллектуальной собственности, одним из участников которых является Россия.

Вместе с тем, отсутствие официальной регистрации перехода прав в результате заключения договора залога в государственном органе для кредитной организации и для 